\title{
Paired-eye comparison of medical therapies for glaucoma
}

This article was published in the following Dove Press journal:

Clinical Ophthalmology

28 September 2010

Number of times this article has been viewed

\author{
Alfred M Solish ${ }^{1,2}$ \\ Friedericke James' \\ John G Walt ${ }^{3}$ \\ Tina $\mathrm{H} \mathrm{Chiang}^{3}$ \\ 'Southern California Glaucoma \\ Consultants, Pasadena CA, USA; ' 2Jules \\ Stein Eye Institute, University of \\ California Los Angeles, Los Angeles, \\ ${ }^{3}$ Allergan Inc., Irvine, CA, USA
}

Objective: To evaluate efficacy and patient preference retrospectively among intraocular pressure (IOP)-lowering prostamide and prostaglandin medications in a real-world clinical setting.

Methods: Chart review of patients with uncontrolled glaucoma or ocular hypertension seen at a private practice clinic $(n=55)$ who received bimatoprost $0.03 \%$ once daily in one eye and either travoprost $0.004 \%$ or latanoprost $0.005 \%$ once daily in the fellow eye. IOP was evaluated at the initial visit and at a follow-up visit scheduled 4-6 weeks later. At the follow-up visit, each patient discussed the clinical results with their physician, chose which medication they preferred to continue using, and were queried regarding the reason for their choice. This paired-eye comparison method is used routinely in clinical practice to assess clinical response and involve patients in decisions regarding treatment. Change in mean IOP from baseline and patient medication choice were the outcome measures.

Results: Bimatoprost-treated eyes $(\mathrm{n}=52)$ had a mean IOP reduction of $2.7 \mathrm{mmHg}$ and travoprost-treated eyes $(\mathrm{n}=47)$ had an average decrease of $1.7 \mathrm{mmHg}(P=0.230)$. Bimatoprost significantly reduced mean IOP (from $19.8 \mathrm{mmHg}$ at baseline to $17.1 \mathrm{mmHg}$ at follow-up, $P<0.0001$ ), as did travoprost (from $19.4 \mathrm{mmHg}$ at baseline to $17.7 \mathrm{mmHg}$ at follow-up, $P=0.009$ ). Latanoprost-treated eyes were excluded from the efficacy analysis due to small sample size $(n=5)$. For continued therapy, patients chose bimatoprost over travoprost by a factor of 2.4 to 1 . Of the 15 patients who gave a reason for their choice, $80 \%$ said their decision was based primarily on IOP change.

Conclusions: Bimatoprost and travoprost were efficacious in reducing IOP among patients with uncontrolled glaucoma and ocular hypertension. Patients preferred bimatoprost over travoprost when trialed in fellow eyes.

Keywords: bimatoprost, travoprost, latanoprost, prostaglandin, prostamide

\section{Introduction}

The prostamide bimatoprost $0.03 \%$ and the prostaglandin analogs travoprost $0.004 \%$ and latanoprost $0.005 \%$ are ocular hypotensive lipids, the newest class of drugs indicated for the lowering of intraocular pressure (IOP) in patients with glaucoma and ocular hypertension. These medications, administered once daily, have greater IOP-lowering efficacy than the beta-blocker timolol. ${ }^{1-3}$

Due to the importance of even small increments of IOP reduction for preservation of visual function among those with glaucoma or ocular hypertension, patients who are not achieving sufficiently low IOP with their current medications may benefit from trying a new regimen. To avoid delay in determining the effect of such changes,
Correspondence: Alfred M Solish Southern California Glaucoma Consultants, 630 South Raymond Ave, Pasadena, CA 91105, USA

Tel + I 626577 III 5

Fax +I 6265771385

Email ultraeye@alum.mit.edu 
a paired-eye comparison was used to assess the efficacy of prostaglandin/prostamide medications in patients who had uncontrolled or poorly controlled IOP.

\section{Methods}

This retrospective chart review of patients participating in individual, within-practice, paired-eye, open-label comparisons included consecutive patients seen at a private practice clinic between September 2002 and May 2005. Patients had a diagnosis of glaucoma or ocular hypertension and their IOP had been uncontrolled in the investigator's clinical judgment. Patients had been clinically judged to be suitable candidates for therapy with agents of the prostamide/prostaglandin class. The three medications studied in this evaluation were bimatoprost $0.03 \%$ (Lumigan $^{\circledR}$; Allergan, Inc., Irvine, CA), travoprost $0.004 \%$ (Travatan ${ }^{\circledR}$; Alcon Laboratories, Inc., Fort Worth, TX), and latanoprost $0.005 \%$ (Xalatan ${ }^{\circledR}$, Pfizer, Inc., New York, NY). Patients were assigned to bimatoprost in one randomly assigned eye and another medication in the fellow eye. The second medication was determined at random, except for patients who were already using one of the prostaglandin/prostamide analogs. These patients switched to use the other two medications.

Patients included in this evaluation were examined by the physician and had IOP measured at the initial visit. Per clinical routine, patients were scheduled for a follow-up visit 4-6 weeks later, when IOP was measured and hyperemia or other side effects were recorded. At the follow-up visit, patients were asked about the eye drops in a general way such as, "How are you doing with the new drops?" or "How are your new drops?" the physician then discussed with each patient the IOP findings for each eye and other aspects of the treatment. After conferring with the physician, patients determined which medication they elected to continue with for their ongoing glaucoma therapy. In some cases, a reason for the patient's choice was noted in the chart. Patient charts were excluded from analysis if they had any ocular surgery between the initial and follow-up visit. The main outcome measures of the chart review were mean change in IOP from baseline, and percentage of patients choosing a particular medication for continued use. Descriptive statistics were calculated. Unpaired $t$-tests were used to evaluate the statistical significance of IOP changes from baseline within a treatment group, and paired $t$-tests were performed to determine statistical significance among treatment groups in the bilateral comparison. $P$ values less than 0.05 were considered statistically significant.

\section{Results Study population}

A total of 91 patients participated in the paired-eye comparison. Of these, 36 were excluded from the chart review analysis; 17 patients' charts were not available at the time of data collection, seven did not have follow-up data, four did not have a confirmatory diagnosis, three did not receive bimatoprost in one of the eyes, two had eye surgery between the baseline and follow-up visit, two patients did not make a clear choice and proceeded to use both study agents, and one individual only used one of the comparative agents.

Fifty patients received bimatoprost in one eye and travoprost in the other eye, and five patients received bimatoprost in one eye and latanoprost in the other eye. Bimatoprost was randomized to the right eye in 30 patients and to the left eye in 25 patients; travoprost was randomized to the right eye in 22 patients and to the left eye in 28 patients; and latanoprost was randomized to the right eye in three patients and to the left eye in two patients. Patient demographics are summarized in Table 1.

Seventy-five percent of patients were taking at least one glaucoma medication, with $42 \%$ of patients on monotherapy and 35\% (19/55) using two or more medications (Table 2). Because the majority of patients $(58 \%, 32 / 55)$ were using latanoprost prior to enrolling in the study (Table 2), few participants were assigned to receive latanoprost during the study.

Table I Patient demographics

\begin{tabular}{lll}
\hline Patients $(\mathrm{n})$ & 55 & \\
Mean age, years (range) & 67 & $(27-90)$ \\
Mean years with glaucoma & 9.35 & \\
Gender, $\mathrm{n}(\%)$ & & \\
$\quad$ Female & 31 & $56.4 \%$ \\
$\quad$ Male & 24 & $43.6 \%$ \\
Race, $\mathrm{n}(\%)$ & & \\
White/Caucasian & 20 & $36.4 \%$ \\
Hispanic & $1 \mathrm{I}$ & $20.0 \%$ \\
Asian/Pacific Islander & 10 & $18.2 \%$ \\
Black/African American & 7 & $12.7 \%$ \\
$\quad$ Not recorded & 7 & $12.7 \%$ \\
Diagnosis, $\mathrm{n}$ (\%)* & & \\
$\quad$ Chronic open-angle glaucoma & 30 & $54.5 \%$ \\
$\quad$ Ocular hypertension & 14 & $25.5 \%$ \\
Low- or normal-tension glaucoma & 7 & $10.5 \%$ \\
Narrow-angle glaucoma & 4 & $7.3 \%$ \\
Pigmentary & 4 & $7.3 \%$ \\
Chronic angle-closure glaucoma & 2 & $3.6 \%$ \\
Suspected glaucoma & 1 & $1.8 \%$ \\
Neovascular glaucoma & 1 & $1.8 \%$ \\
\hline
\end{tabular}

Note: *Some patients had a diagnosis of more than one type of glaucoma. 
Table 2 Glaucoma medications used prior to study

\begin{tabular}{lll}
\hline & $\mathbf{n}$ & $\%$ \\
\hline Number of medications & & \\
0 & 13 & $23.7 \%$ \\
$\mathrm{I}$ & 23 & $41.8 \%$ \\
2 & $\mathrm{II}$ & $20.0 \%$ \\
3 & 7 & $12.7 \%$ \\
4 & $\mathrm{I}$ & $1.8 \%$ \\
Previous medications* & & \\
Latanoprost & 32 & $58.2 \%$ \\
Brimonidine/adrenergic agonist & $\mathrm{II}$ & $20.0 \%$ \\
Dorzolamide/timolol combination & 10 & $18.2 \%$ \\
Timolol/beta-blocker & 10 & $18.2 \%$ \\
Dorzolamide/carbonic anhydrase inhibitor & 5 & $9.1 \%$ \\
Carbachol & $\mathrm{I}$ & $1.8 \%$ \\
Travoprost & $\mathrm{I}$ & $1.8 \%$ \\
None & 13 & $23.6 \%$ \\
\hline
\end{tabular}

Note: *Some patients were receiving more than one medication prior to study therapy.

The median interval between the baseline and follow-up visits was 42 days (mean 72.7 days), and 10 patients had their follow-up visit more than 90 days after the baseline visit. Data were obtained for all outcome measures for all patients, except for three patients receiving bilateral bimatoprost or travoprost, for whom IOP-lowering data were not documented in the medical chart at the follow-up visit.

\section{IOP reduction}

Bimatoprost and travoprost significantly reduced IOP from baseline during the study period (Figure 1). For eyes

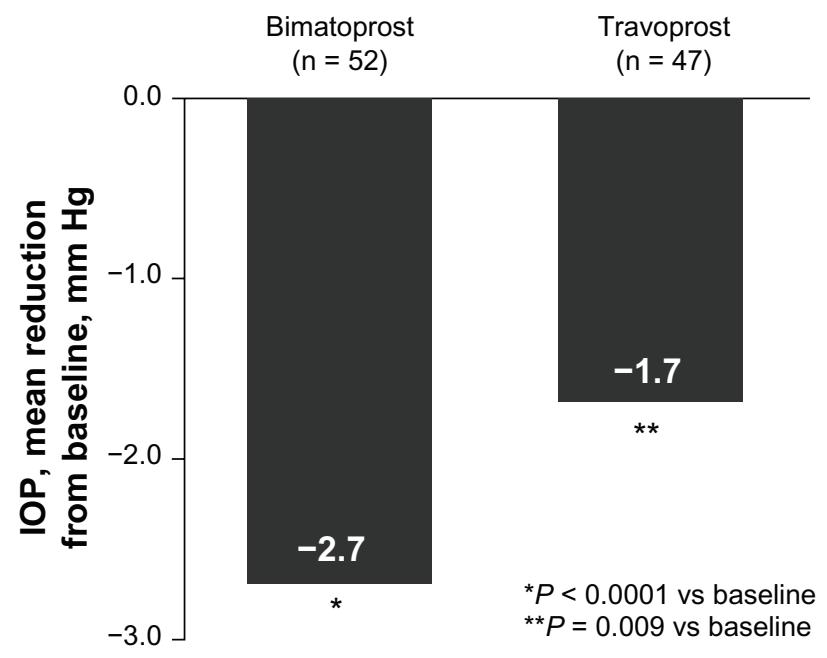

Figure I Change in mean IOP from baseline. IOP reduction seen over 4-6 weeks of QD treatment. Baseline mean IOP: bimatoprost $19.8 \mathrm{mmHg}$; travoprost $19.4 \mathrm{mmHg}$. Follow-up IOP: bimatoprost $17.1 \mathrm{mmHg}$; travoprost $17.2 \mathrm{mmHg} . P=0.230$ for bimatoprost versus travoprost change bilateral paired-eye analysis of change in IOP from baseline.

Abbreviation: IOP, intraocular pressure. receiving bimatoprost with documented IOP measurement at baseline and at follow-up ( $\mathrm{n}=52)$, IOP decreased by $2.7 \mathrm{mmHg}$ (standard deviation $=4.2 \mathrm{mmHg}$ ), a significant reduction $(P<0.0001)$ versus baseline. Mean $( \pm$ standard deviation) baseline IOP for bimatoprost-treated eyes was $19.8 \pm 4.9 \mathrm{mmHg}$ (range 10-34) and dropped to $17.1 \pm 4.9 \mathrm{mmHg}$ (range 19-37) at the end of the study period. For travoprost-treated eyes with documented IOP measurement at baseline and at follow-up $(n=47)$, IOP was reduced from a baseline value of $19.4 \pm 4.1 \mathrm{mmHg}$ (range $12-31$ ) to $17.7 \pm 4.2 \mathrm{mmHg}$ (range 9-29) at the end of the study period, for a decrease of $1.7 \mathrm{mmHg}(P=0.009$ versus baseline). The numeric magnitude of mean IOP reduction with bimatoprost was larger than with travoprost $(2.7 \mathrm{mmHg}$ versus $1.7 \mathrm{mmHg}$ decrease), but the difference did not reach statistical significance $(P=0.230)$.

In eyes receiving latanoprost $(\mathrm{n}=5)$, mean baseline IOP was $19.6 \pm 4.7 \mathrm{mmHg}$ (range 15-26), and IOP at follow-up averaged $16.2 \pm 2.5 \mathrm{mmHg}$ (range 14-20), for a reduction of $3.4 \pm 3.2 \mathrm{mmHg}$. This difference was not statistically significant $(P=0.077)$, probably because of the small sample size.

\section{Patient choices of medication}

At the follow-up visit, the physician discussed the clinical outcomes with each patient, and each patient chose which medication they would prefer to continue using. Patients who received bimatoprost in one eye and travoprost in the fellow eye chose to continue with bimatoprost over travoprost by a factor of 2.4 to 1 (Figure 2). Nearly seven of 10 patients chose bimatoprost $(68 \%, 34 / 50), 28 \%$ of patients $(14 / 50)$ chose travoprost, and $4 \%(2 / 50)$ chose neither. The two patients who chose neither option had used latanoprost

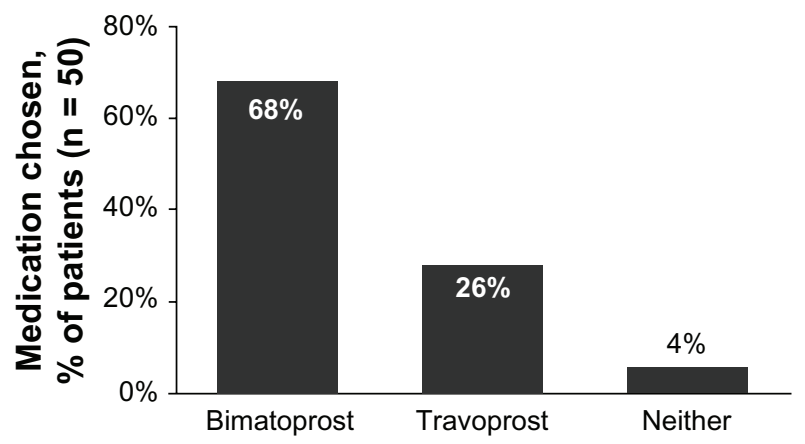

Figure 2 Glaucoma medications chosen by patients. After 4-6 weeks of bilateral glaucoma therapy, patients chose which medication they would prefer to continue using as their ongoing regimen. Data shown are for patients who received bimatoprost in one eye and travoprost in the fellow eye. 
prior to the study, and elected to continue with it afterwards. Among the five patients who received bilateral bimatoprost or latanoprost, three chose to continue with bimatoprost, one chose latanoprost, and one chose neither (this patient had been using travoprost prior to the study and chose to continue with it).

Table 3 shows the primary factor that patients stated influenced their choice of medication. Among the 15 patients who stated a reason, most $(80 \%, 12 / 15)$ cited improvement in IOP as the primary factor in their decision. A majority of these patients $(83 \%, 10 / 12)$ preferred bimatoprost over the agent they had used in the fellow eye.

Other reasons offered by patients for determination of medication choice were "pressure change plus better side effect profile", "convenience", and "price", cited by one patient each (medications chosen were travoprost, and latanoprost, respectively). No patients cited "side effect profile" as a primary influence on their medication choice. Looking at the entire study population analyzed $(n=55)$, hyperemia was reported by eight patients, with six reporting hyperemia in both eyes, one reporting hyperemia in the bimatoprost-treated eye only, and one reporting hyperemia in the travoprost-treated eye only.

\section{Discussion}

Patients with glaucoma or ocular hypertension who did not have sufficient IOP control with their current medication regimens instilled bimatoprost in one eye and either travoprost or latanoprost in the other eye. Significant IOP reductions were observed for bimatoprost- and travoprosttreated eyes, consistent with published results. ${ }^{1-4}$

Relatively few studies have directly compared the efficacy of prostaglandin/prostamide glaucoma therapies. In a meta-analysis of all head-to-head randomized, investigatormasked direct comparisons of latanoprost, bimatoprost, and travoprost, bimatoprost was more efficacious at lowering IOP than travoprost in the two direct comparisons identified (involving 150 patients), and bimatoprost was found to

Table 3 Factors in patients' choice of glaucoma medication

\begin{tabular}{lll}
\hline Reasons not stated & 40 & $72.7 \%$ \\
Reasons stated & 15 & $27.3 \%$ \\
Specific reasons $(\mathrm{n}=15)$ & & \\
$\quad$ IOP improvement & 12 & $80.0 \%$ \\
Side effect profile & 0 & $0.0 \%$ \\
IOP improvement and better side effect profile & $\mathrm{I}$ & $6.7 \%$ \\
Convenience & $\mathrm{I}$ & $6.7 \%$ \\
Price & $\mathrm{I}$ & $6.7 \%$ \\
\hline
\end{tabular}

Abbreviation: IOP, intraocular pressure. be more efficacious than latanoprost in six head-to-head studies identified (involving 460 patients). ${ }^{4}$ Our study may not have been adequately powered to detect statistically significant differences among therapies. However, for the two therapies where we detected a significant IOP decline from baseline (bimatoprost and travoprost), bimatoprost showed qualitatively greater IOP reduction than travoprost, consistent with a report by Holmstrom et al. ${ }^{4}$

An important limitation of this assessment was the fact that relatively few eyes were randomized to receive latanoprost. Because nearly $60 \%$ of study participants had been receiving latanoprost prior to the study, only five patients received latanoprost as one of the comparators. Therefore, for these patients, the bilateral comparison was limited to travoprost and bimatoprost. Because of the small sample size, the results with latanoprost may be difficult to generalize. Use of a larger study population, or employment of a multiple-study site design in future trials may result in a patient population that is more evenly distributed among the cohorts.

It should be noted that our results are consistent with those of a large-scale "real-world" study, in which more than 15,000 glaucoma patients on latanoprost were switched to bimatoprost in a nationwide health maintenance organization. ${ }^{5}$ In that study, patients switching to bimatoprost experienced statistically significant IOP reduction, and few reverted to their previous medication. ${ }^{5}$

Nonadherence to glaucoma treatment regimens is a significant problem, in large part because glaucoma is chronic, progressive, and symptom-free in its early stages. ${ }^{6-8}$ In the treatment practice described in this report, patients chose which medication to continue using after consulting with the physician. The patient-physician partnership in medical decision-making is increasing as patients become more empowered through consumerism and access to independent information resources, such as the Internet. ${ }^{9}$ A majority of patients in this study who gave a reason for their choice cited IOP-lowering efficacy, as opposed to side effects or other aspects of the medication immediately perceptible to the patient. Our results, while preliminary, raise the intriguing question of whether patients who are involved in their medical decision-making might also have improved adherence to their glaucoma regimens. Further study may be warranted.

\section{Conclusion}

After direct comparisons between glaucoma drugs trialed in each eye, patients preferred bimatoprost over travoprost by a factor of 2.4 to 1 . Today's therapeutic armamentarium offers multiple choices for achieving target IOP. Physicians 
may wish to consider a simple bilateral trial such as ours for their glaucoma patients who are not achieving adequate IOP control with their current medication regimens.

\section{Acknowledgment}

This research was sponsored by Allergan, Inc., Irvine, CA. John Walt and Tina Chiang are employees of Allergan, Inc.

\section{Disclosure}

A preliminary report of this research was presented at the annual meeting of the American Glaucoma Society, March 2-5, 2006, San Francisco, CA. AMS and FJ declare that they have no competing interests.

\section{References}

1. Cohen JS, Gross RL, Cheetham JK, et al. Two-year double-masked comparison of bimatoprost with timolol in patients with glaucoma or ocular hypertension. Surv Ophthalmol. 2004;49 Suppl 1:S45-S52.

2. Fellman RL, Sullivan EK, Ratliff M, et al. Travoprost Study Group: Comparison of travoprost $0.0015 \%$ and $0.004 \%$ with timolol $0.5 \%$ in patients with elevated intraocular pressure: A 6-month, masked, multicenter trial. Ophthalmology. 2002;109:998-1008.
3. Hedman K, Alm A. A pooled-data analysis of three randomized, double-masked, six-month clinical studies comparing the intraocular pressure reducing effect of latanoprost and timolol. Eur J Ophthalmol. 2000;10:95-104.

4. Holmstrom S, Buchholz P, Walt J, et al. Analytic review of bimatoprost, latanoprost, and travoprost in primary open angle glaucoma. Curr Med Res Opin. 2005;21:1875-1883.

5. Law SK, Song BJ, Fang E, Caprioli J. Feasibility and efficacy of a mass switch from latanoprost to bimatoprost in glaucoma patients in a prepaid health maintenance organization. Ophthalmology. 2005; 112:2123-2130.

6. Sleath B, Robin AL, Covert D, et al. Patient-reported behavior and problems in using glaucoma medications. Ophthalmology. 2006;113: 431-436.

7. Tsai JC, McClure CA, Ramos SE, et al. Compliance barriers in glaucoma: A systematic classification. J Glaucoma. 2003;12:393-398.

8. Wilensky J, Fiscella RG, Carlson AM, et al. Measurement of persistence and adherence to regimens of IOP-lowering glaucoma medications using pharmacy claims data. Am J Ophthalmol. 2006;141 Suppl 1:S28-S33.

9. McGregor S. Roles, power, and subjective choice. Patient Educ Couns. 2006;60:5-9.
Clinical Ophthalmology

\section{Publish your work in this journal}

Clinical Ophthalmology is an international, peer-reviewed journal covering all subspecialties within ophthalmology. Key topics include: Optometry; Visual science; Pharmacology and drug therapy in eye diseases; Basic Sciences; Primary and Secondary eye care; Patien Safety and Quality of Care Improvements. This journal is indexed on

Submit your manuscript here: http://www.dovepress.com/clinical-ophthalmology-journal

\section{Dovepress}

PubMed Central and CAS, and is the official journal of The Society of Clinical Ophthalmology (SCO). The manuscript management system is completely online and includes a very quick and fair peer-review system, which is all easy to use. Visit http://www.dovepress.com/ testimonials.php to read real quotes from published authors. 